\title{
Opioid Receptors in the Nucleus Accumbens Regulate Attentional Learning in the Blocking Paradigm
}

\author{
Mihaela D. Iordanova, Gavan P. McNally, and R. Frederick Westbrook \\ School of Psychology, The University of New South Wales, Sydney, New South Wales 2052, Australia
}

Fear learning depends on prediction error, or the discrepancy between the actual and expected outcome of a conditioning trial. These experiments used blocking and unblocking designs to study the role of opioid receptors in the nucleus accumbens (Acb) in predictive fear learning. Previous fear conditioning to a context blocked later fear conditioning to a conditioned stimulus (CS) in that context. Fear learning proceeded normally (i.e., unblocking occurred) if the CS signaled a more intense footshock than was used during previous context conditioning. Blocking and unblocking were mediated by Acb opioid receptors. Acb microinjections of a nonselective opioid receptor agonist prevented blocking, whereas a nonselective antagonist prevented unblocking. Examination of the associative mechanism for blocking and unblocking revealed that Acb opioid receptors mediate indirect predictive learning by controlling learned variations in attention. $\mu$-Opioid and $\kappa$-opioid receptors contribute to this learned regulation of attention because Acb microinjections of a $\mu$-opioid receptor agonist impaired, whereas a $\kappa$-opioid receptor agonist facilitated, blocking. Acb microinjections of a $\mu$-opioid receptor antagonist also prevented unblocking. Microinjections of a $\delta$-opioid receptor agonist or antagonist were without effect on blocking and unblocking. Our data show that the Acb mediates attentional selection between competing predictors of motivationally significant events to enable learning about the best predictor of such events at the expense of worse predictors. During fear learning, Acb $\mu$-opioid receptors upregulate attention to conditioned stimuli that are predictive of shock, whereas $\kappa$-opioid receptors downregulate attention to conditioned stimuli that are redundant or noninformative predictors of shock.

Key words: learning; blocking; unblocking; attention; opioid receptor; prediction error

\section{Introduction}

The failure of pavlovian fear conditioning termed the "blocking effect" (Kamin, 1968) was important for the development of error-correction models of associative learning (for review, see Dickinson, 1980; Rescorla, 1988). Kamin (1968) subjected rats to pairings of CSA with footshock (stage I). Rats then received a compound of CSA and CSB, followed by footshock (stage II). Previous conditioning of CSA blocked the development of fear to CSB because there was no prediction error during stage II. For control rats subjected only to stage II compound pairings of CSA and CSB with shock, fear learning to CSB proceeded normally. Blocking does not occur if the CSA-CSB compound signals an increase in the intensity of the unconditioned stimulus (US) from that used to train CSA; instead conditioning to CSB proceeds normally (so-called "unblocking") because there is prediction error during stage II. Prediction error can have a direct or indirect effect on fear conditioning. An indirect effect is achieved by selective attention: if prediction error is large, attention to the conditioned stimulus (CS) is maintained, and it associates with the US (unblocking); if prediction error is small, attention is initially directed toward the CS but is then withdrawn, and the association

\footnotetext{
Received Nov. 1, 2005; revised Feb. 23, 2006; accepted Feb. 25, 2006

This work was supported by Australian Research Council Discovery Project Grant A10007151 to R.F.W.

Correspondence should be addressed to Dr. R. Frederick Westbrook, School of Psychology, The University of New

South Wales, Sydney, New South Wales 2052, Australia. E-mail: f.westbrook@unsw.edu.au.

DOI:10.1523/JNEUROSCI.4679-05.2006

Copyright $\odot 2006$ Society for Neuroscience $\quad 0270-6474 / 06 / 264036-10 \$ 15.00 / 0$
}

is impaired (blocking). The neural mechanisms for indirect predictive fear learning are unknown.

Studies of reward-responsive midbrain dopamine (DA) neurons in monkeys indicate that the firing of these cells is closely linked to predictive learning. These cells display high levels of firing to unexpected rewards and low levels of firing to expected rewards (Waelti et al., 2001). Conversely, these cells show high levels of firing to conditioned stimuli that reliably predict rewards and low levels of firing to conditioned stimuli that are not predictive of rewards (Waelti et al., 2001). Neuroimaging studies in human participants reveal similar changes in target regions of midbrain DA cells, the ventral striatum and ventral putamen (Pagnoni et al., 2002; O’Doherty et al., 2003). These changes also occur during blocking. For example, reward-responsive cells in monkey midbrain acquire stronger responses to a rewardpredicting stimulus than a blocked stimulus (Waelti et al., 2001). In human participants, the ventral putamen also shows larger responses to a reward-predicting stimulus than a blocked stimulus (Tobler et al., 2006). These findings suggest that levels of DA in the ventral striatum contribute to predictive learning.

Opioid receptors in the nucleus accumbens (Acb) modulate DA levels (Spanagel et al., 1992; Hirose et al., 2005). In these experiments, we studied the role of Acb opioid receptors in predictive fear learning. We used blocking and unblocking preparations to determine whether Acb opioid receptors contributed to direct or indirect predictive fear learning. We hypothesized that Acb infusions of an opioid receptor agonist would prevent the 
loss of attention normally suffered by a blocked CS and so would prevent blocking, whereas antagonism of opioid receptors would facilitate the loss of attention to an otherwise predictive CS and so would prevent unblocking.

\section{Materials and Methods \\ Subjects}

The subjects were 266 experimentally naive male Wistar rats weighing between 260 and $320 \mathrm{~g}$. They were obtained from a commercial supplier (Gore Hill Research Laboratories, Sydney, New South Wales, Australia). Rats were housed in plastic boxes $(22 \mathrm{~cm}$ high $\times 65 \mathrm{~cm}$ long $\times 40 \mathrm{~cm}$ wide). Food and water were available continuously in the boxes and cages that were kept in a colony room under natural lighting. The experimental procedures were approved by the Animal Ethics Committee at the University of New South Wales and conducted in accordance with the National Institutes of Health Guidelines for the Care and Use of Laboratory Animals (publication DHHS NIH 86-23). All experimental procedures took place between 9:00 A.M. and 5:00 P.M.

\section{Drugs}

Fifteen micrograms (39.91 nм) of the opioid agonist morphine hydrochloride (a generous gift from GlaxoSmithKline, Boronia, Victoria , Australia); $5 \mu \mathrm{g}$ (12.64 nM) of the antagonist naloxone hydrochloride (Sigma, Sydney, Australia); $0.5 \mu \mathrm{g}(0.97 \mathrm{~nm})$ of the $\mu$ receptor agonist D-Ala2-NMe-Phe4-Glycol5-enkephalin (DAMGO); $5 \mu \mathrm{g}$ (4.5 nM) of the $\mu$ receptor antagonist D-Phe-Cys-Tyr-D-Trp-Arg-Thr-Pen-Thr- $\mathrm{NH}_{2}$ (CTAP); $2.5 \mu \mathrm{g}(3.87 \mathrm{nM})$ of the $\delta$ receptor agonist [D-Ala2-N-Me-Phe4-Gly-ol] enkephalin (DPDPE); $2.5 \mu \mathrm{g}(5.28 \mathrm{nM}), 7.5 \mu \mathrm{g}$ (15.84 nM), or $10 \mu \mathrm{g}$ $(21.12 \mathrm{nM})$ of the $\delta$ receptor antagonist Naltrindole; $5 \mu \mathrm{g}(12.32 \mathrm{nM})$ of the $\kappa$ receptor agonist U50488; and $5 \mu \mathrm{g}(6.56 \mathrm{nM})$ of the $\kappa$ receptor antagonist nor-binaltorphimine dihydrochloride (Nor-BNI; all opioid compounds were obtained from Tocris-Cookson, Bristol, UK) were each dissolved in $1 \mu \mathrm{l}$ of sterile non-pyrogenic saline $0.9 \%$ (w/v). Nonpyrogenic saline $(0.9 \% \mathrm{w} / \mathrm{v})$ was used for control injections. Solutions were microinjected in a volume of $1.0 \mu \mathrm{l}$ across a period of $2 \mathrm{~min}$, and the microinjection cannula was left in place for an additional $1 \mathrm{~min}$ to permit diffusion. During sham microinjections, rats were connected to the infusion pump, but no needle was inserted into the guide cannula, and no fluids were microinjected.

\section{Surgery and histology}

Approximately $1 \mathrm{~h}$ before surgery, rats were injected intraperitoneally with a prophylactic $(0.3 \mathrm{ml})$ dose of a $300 \mathrm{mg} / \mathrm{ml}$ solution of procaine penicillin. They were then injected intraperitoneally with $1.3 \mathrm{ml} / \mathrm{kg}$ of the anesthetic ketamine (Ketapex; Apex Laboratories, Sydney, Australia) at a concentration of $100 \mathrm{mg} / \mathrm{ml}$ and with $0.3 \mathrm{ml} / \mathrm{kg}$ of the muscle relaxant xylazine (Rompun; Bayer, Sydney, Australia) at a concentration of 20 $\mathrm{mg} / \mathrm{ml}$. Each rat was placed in the stereotaxic apparatus (model 900; Kopf Instruments, Tujunga, CA) while maintaining the incisor bar at $\sim 3.3$ $\mathrm{mm}$ below horizontal to achieve a flat skull position, and a 26 gauge guide cannula (Plastics One, Roanoke, VA) was implanted into the right hemisphere of the brain. The tip of the guide cannula was aimed at the Acb or the dorsally lying caudate-putamen $(\mathrm{CPu})$ by positioning it 7.0 or 5.0 $\mathrm{mm}$ below bregma, respectively, through a hole drilled $1.4 \mathrm{~mm}$ anterior and $1.8 \mathrm{~mm}$ lateral to bregma. The guide cannula was fixed in position with dental cement and anchored by Super Glue (Selleys, Sydney, Australia). A dummy cannula was kept in the guide at all times, except during microinjections when a 33 gauge microinjection cannula was inserted into the guide cannula and connected to a $25 \mu$ l glass syringe attached to an infusion pump (Harvard Apparatus, South Natick, MA). The microinjection cannula projected an additional $1 \mathrm{~mm}$ ventral to the tip of the guide cannula. Rats were allowed $7 \mathrm{~d}$ to recover from surgery, during which time they were handled and weighed daily.

At the end of the experiment, rats were killed with an overdose of sodium pentobarbital, and their brains were removed. Unfixed brains were sectioned coronally at $40 \mu \mathrm{m}$ through the Acb. Every fourth section was collected on a slide, and the sections were stained with cresyl violet. Cannula placements were verified using the boundaries defined by Paxinos and Watson (1998). The sections were examined under a microscope by a trained observer who was unaware of the subjects' group designations. The data of any rat were excluded from the statistical analysis if the cannula tip was $>0.5 \mathrm{~mm}$ outside the $\mathrm{Acb}$, or if the region had sustained extensive damage. Figure 1 shows the area within which the microinjection tips were located.

\section{Apparatus}

Two chambers $(20 \mathrm{~cm}$ high $\times 23 \mathrm{~cm}$ long $\times 21 \mathrm{~cm}$ wide $)$ were used to shock the rats and to test for fear reactions (freezing) to the previously shocked chamber (or context). The front and rear walls of these chambers, as well as the hinged lid, were constructed of Perspex, and the end walls were made of stainless steel. The floor in each chamber consisted of stainless steel rods, $2 \mathrm{~mm}$ in diameter, spaced $10 \mathrm{~mm}$ apart (center to center). The US was a $1.0 \mathrm{~s}, 0.8 \mathrm{~mA}$ or $0.4 \mathrm{~mA}$ unscrambled AC $50 \mathrm{~Hz}$ shock from a constant-current generator that was delivered to the floor of each chamber. The current available to each floor could be adjusted using an in-line milliampere meter. Each chamber stood $5 \mathrm{~cm}$ above a tray of paper pellet bedding (Fibercycle, Mudgeeraba, Australia) that was changed daily. After removal of a rat, the floor of each chamber was cleaned with a solution of acetic acid $(0.5 \%)$ to eliminate any residue and provide a distinctive odor. These two chambers were located within separate compartments of a wooden cabinet. The door of each compartment was kept open to permit observation of the rat.

A second set of two chambers $(16 \mathrm{~cm}$ height $\times 40 \mathrm{~cm}$ length $\times 26 \mathrm{~cm}$ width) was used to test performance to the auditory CS. The front of these chambers was constructed of Perspex. The floor and side and rear walls were made of plastic, and the roof was made of stainless steel rods. After removal of a rat, the floor of each chamber was wiped with a $1.0 \%$ solution of vanilla essence (Queen Fine Foods, Alderly, Australia) to eliminate any residue and provide a distinctive odor. These chambers were located on the roof of the wooden cabinet that contained the shock chambers.

The discrete auditory CS was $10 \mathrm{~s}$ in duration and consisted of an 81 $\mathrm{dB}, 10 \mathrm{~Hz}$ clicker (rise time, $<10 \mu \mathrm{s}$; decay time, $250 \mu \mathrm{s}$ ) delivered from a speaker situated in the ceiling of the experimental room. The background noise in the room was $69 \mathrm{~dB}$. The stimulus and background intensities were measured with a sound-level meter (A Scale, type 2235; Brüel-Kjaer Instruments, Marlborough, MA), the microphone of which was placed in the center of each chamber. The room that contained the experimental chambers was illuminated by eight $60 \mathrm{~W}$ standard incandescent lights located in the ceiling. All training and test sessions were recorded on videotape via cameras mounted on a wall opposite the chambers. The camera was connected to a monitor and video recorder located in an adjacent room.

\section{Behavioral procedures}

Experiment 1: role of Acb opioid receptors in blocking and unblocking. On day 1 (stage I), rats were transported to the laboratory. Rats in the control groups were handled, whereas those receiving pretraining were placed in the conditioning chamber. Three minutes after placement, they received three shocks spaced $3 \mathrm{~min}$ apart. For rats in the block groups, each shock was $0.8 \mathrm{~mA}$ for $1.0 \mathrm{~s}$, whereas for those in the unblock groups, each shock was $0.4 \mathrm{~mA}$ for $1.0 \mathrm{~s}$. Rats remained in the chamber for an additional $30 \mathrm{~s}$ after the third shock. On day 2 (stage II), all rats received an infusion into the Acb. Those in the block-morphine and control-morphine groups received an infusion of morphine; those in the block-saline, unblocksaline, and control-saline groups were infused with saline; and rats in the unblock-naloxone and control-naloxone groups received an infusion of naloxone. Twenty minutes later, all rats were placed in the conditioning chambers for $5 \mathrm{~min}$ and exposed to a $10 \mathrm{~s}$ clicker, the termination of which co-occurred with the onset of shock $(0.8 \mathrm{~mA}$ for $1.0 \mathrm{~s})$. Rats received a second clicker CS-shock pairing 220 s later. They remained in the chambers for $60 \mathrm{~s}$ after the second clicker-shock pairing. Six hours later, rats that had been infused with morphine or naloxone received an infusion of saline, and those infused with saline now received an infusion of morphine or naloxone. On days 3 and 4, rats were tested in the conditioning context without the CS and in the Perspex chamber with the CS (presented 2 min after placement in the chamber). Before the test, rats received a sham microinjection. Each test was $10 \mathrm{~min}$ in duration. How- 
ever, the statistical analysis was conducted on the levels of freezing across the initial 2 min of the context test and the initial 2 min of CS test. The order in which subjects in each group were tested in the chambers was counterbalanced: one-half of the rats in each group were tested on day 3 in the conditioning chamber (without the CS) and on day 4 in the Perspex chamber (with the CS); the remainder was tested on day 3 in the Perspex chamber (with the CS) and on day 4 in the conditioning chamber (without the CS).

Experiment 2: role of Acb opioid receptors in indirect predictive learning. On days 1-3 (stage I), rats received a shocked exposure to the context. Each exposure lasted $4 \mathrm{~min}$, and a single $0.8 \mathrm{~mA}, 1.0 \mathrm{~s}$ shock was administered 3 min after placement in the context. On days 4 and 5 (stage II), all rats received a CS-shock pairing in the context. The CS was presented 2 min, $50 \mathrm{~s}$ after placement in the conditioned context, and rats remained in the context for $60 \mathrm{~s}$ after shock. All rats received an infusion into the Acb $20 \mathrm{~min}$ in advance of each CS-shock pairing. There were four groups: saline-saline, morphine-morphine, saline-morphine, and morphine-saline. The first group designation refers to the type of infusion before the first stage II trial, and the second group designation refers to the type of infusion before the second stage II trial. Rats were tested for fear of the context and of the CS in the manner described previously.

Experiments $3 a$ and $3 b$ : role of $A c b \mu$-and $\delta$-opioid receptors in blocking and unblocking. In experiment $3 \mathrm{a}$, the procedures were identical to those described. On day 1 (stage I), pretrained rats received three foot shocks in the context, whereas control rats were handled. Among pretrained rats, each shock was $0.8 \mathrm{~mA}$ for $1.0 \mathrm{~s}$ for those in the block groups and $0.4 \mathrm{~mA}$ for $1.0 \mathrm{~s}$ for those in the unblock groups. On day 2 (stage II), rats in six of the groups received an infusion into the Acb. Rats in the block groups received an infusion of the $\mu$-opioid receptor agonist DAMGO, the $\delta$-agonist DPDPE, or saline; those in the unblock groups received an infusion of the $\mu$-opioid receptor antagonist CTAP, the $\delta$-opioid receptor antagonist Naltrindole, or saline. A final group of pretrained rats received an infusion of CTAP into the $\mathrm{CPu}$. Non-pretrained (control) rats received an infusion of saline. Twenty minutes after infusion, all rats received the CS-shock pairings in the manner described previously. Six hours later, pretrained rats that had been infused with a drug now received saline, whereas pretrained rats infused with saline now received an infusion of DAMGO, DPDPE, CTAP, or Naltrindole.

Experiment $3 \mathrm{~b}$ studied the dose-response properties of $\delta$-opioid receptor antagonism $(0,2.5,7.5$, or $10.0 \mu \mathrm{g})$ on unblocking. The procedures were identical to those described for experiment $3 \mathrm{a}$, with the single exception that the CS and context tests were $1 \mathrm{~min}$ in duration.

Experiment 4: role of $A c b \kappa$-opioid receptors in blocking. The procedures were identical to those of experiment 1 , except that (1) pretrained rats in the block and control groups were infused with the $\kappa$-opioid agonist U50488, the $\kappa$-opioid receptor antagonist Nor-BNI, or saline before stage II, and (2) non-pretrained rats were infused with U50488, Nor$\mathrm{BNI}$, or saline. Six hours later, pretrained rats that had been infused with a drug now received saline, whereas pretrained rats infused with saline now received an infusion of U50488 or Nor-BNI.

\section{Scoring}

Freezing was defined as the absence of all movements, except those related to breathing (Blanchard and Blanchard, 1969). The behavior of each rat was recorded on videotape, and freezing was rated with a timesampling procedure in which each rat was observed every $2 \mathrm{~s}$ and scored as either freezing or moving. A percentage score was calculated for the proportion of the total observation period that each rat spent freezing. Freezing was rated by two observers, one of whom was unaware of the subject's group designation. There was a high degree of agreement between the two observers: the Pearson product-moment correlation between their ratings was $>0.98$.

\section{Statistics}

The data were analyzed by ANOVA testing sets of planned contrasts. The family-wise error rate was controlled for each family of contrasts tested using the Bonferroni inequality procedure (Stevens, 1986). Significance was set at the 0.05 level.
Table 1. Behavioral designs for experiments 1-4

\begin{tabular}{|c|c|c|c|}
\hline Group & Stage I & Stage II & Test \\
\hline & $\begin{array}{l}+=0.8 \mathrm{~mA} \\
+=0.4 \mathrm{~mA}\end{array}$ & & \\
\hline \multicolumn{4}{|l|}{ Experiment 1} \\
\hline \multicolumn{4}{|l|}{ Control-saline } \\
\hline \multicolumn{4}{|l|}{ Control-morphine } \\
\hline \multicolumn{4}{|l|}{ Control-naloxone } \\
\hline Block-saline & Cxt: +++ & $\mathrm{Cxt}: \mathrm{CS}+\mathrm{CS}+$ & $\mathrm{Cxt}, \mathrm{CS}$ \\
\hline Block-morphine & Cxt: +++ & & \\
\hline Unblock-saline & Cxt: ${ }^{+++}$ & & \\
\hline Unblock-naloxone & $\mathrm{Cxt}^{+++}$ & & \\
\hline \multicolumn{4}{|l|}{ Experiment 2} \\
\hline Saline-saline & Cxt: +++ & & \\
\hline Morphine-morphine & Cxt: +++ & & \\
\hline Saline-morphine & Cxt: +++ & $\mathrm{Cxt}: \mathrm{CS}+\mathrm{CS}+$ & $\mathrm{Cxt}, \mathrm{CS}$ \\
\hline Morphine-saline & Cxt: +++ & & \\
\hline \multicolumn{4}{|l|}{ Experiment 3} \\
\hline \multicolumn{4}{|l|}{ Control-saline } \\
\hline Block-saline & Cxt: +++ & & \\
\hline Unblock-saline & $\mathrm{Cxt}^{+++}$ & & \\
\hline Block-DAMGO & Cxt: +++ & & \\
\hline Block-DPDPE & Cxt: +++ & $\mathrm{Cxt}: \mathrm{CS}+\mathrm{CS}+$ & $\mathrm{Cxt}, \mathrm{CS}$ \\
\hline Unblock-CTAP & Cxt: ${ }^{+++}$ & & \\
\hline Unblock-naltrindole & $\mathrm{Cxt}^{+++}$ & & \\
\hline Unblock-CTAP CPu & Cxt: ${ }^{+++}$ & & \\
\hline \multicolumn{4}{|l|}{ Experiment 3b } \\
\hline \multicolumn{4}{|l|}{ Control-saline } \\
\hline Block-saline & Cxt: +++ & & \\
\hline Unblock-saline & Cxt: ${ }^{+++}$ & & \\
\hline Unblock-2.5 $\mu \mathrm{g}$ of naltrindole & Cxt: ${ }^{+++}$ & $\mathrm{Cxt}: \mathrm{CS}+\mathrm{CS}+$ & \\
\hline Unblock-7.5 $\mu \mathrm{g}$ of naltrindole & $\mathrm{Cxt}^{+++}$ & & \\
\hline Unblock-10 $\mu \mathrm{g}$ of naltrindole & $\mathrm{Cxt}^{+++}$ & & \\
\hline \multicolumn{4}{|l|}{ Experiment 4} \\
\hline \multicolumn{4}{|l|}{ Control-saline } \\
\hline \multicolumn{4}{|l|}{ Control-U50488 } \\
\hline \multicolumn{4}{|l|}{ Control-Nor-BNI } \\
\hline Block-saline & Cxt: +++ & $\mathrm{Cxt}: \mathrm{CS}+\mathrm{CS}+$ & $\mathrm{Cxt}, \mathrm{CS}$ \\
\hline Block-U50488 & Cxt: +++ & & \\
\hline Block-Nor-BNI & Cxt: +++ & & \\
\hline
\end{tabular}

Cxt, Context $;+++,{ }^{+++}$, three footshocks.

\section{Results \\ Experiment 1: role of Acb opioid receptors in blocking and unblocking}

In experiment 1 , we studied the role of Acb opioid receptors in blocking and unblocking of pavlovian fear learning. The design consisted of seven groups (Table 1). Three control groups received no stage I training. Four experimental groups received context-shock pairings in stage I. The two groups in the block condition received a high-intensity US, whereas the two groups in the unblock condition received a low-intensity US. In stage II, all groups received CS- high-intensity US pairings in the distinctive context. Stage II training was preceded by Acb infusions. The block groups received an infusion of saline or morphine (an opioid receptor agonist), whereas the unblock groups received an infusion of saline or naloxone (an opioid receptor antagonist). The control groups received infusions of saline, morphine, or naloxone. Finally, rats were tested with the CS in the different context and in the training context without the CS. The order of these tests was counterbalanced such that one-half of the rats in each group were tested with the CS in the different context and then $24 \mathrm{~h}$ later in the training context, whereas the remaining rats received the reverse order. 


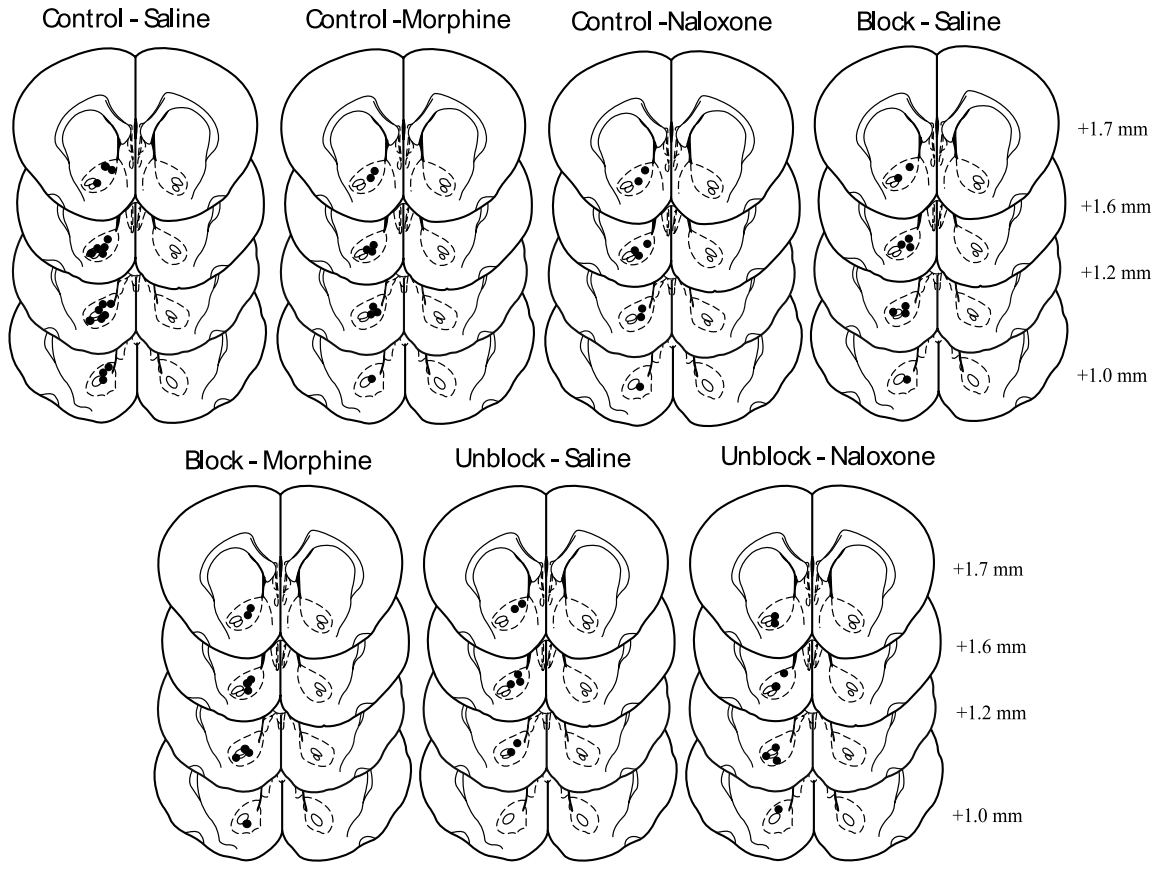

Figure 1. Location of microinjection cannula tips in the Acb in experiment 1. The placements represented are from all rats included in the final analysis. Atlas templates were adapted from Paxinos and Watson (1998) (distances in millimeters from bregma).

\section{Histology}

Figure 1 shows the location of microinjection tips. A total of 11 animals were excluded from the experiment because of incorrect cannula placement. Thus, 67 animals were included in the analyses (control-saline group, $n=17$; controlmorphine group, $n=9$; control-naloxone group, $n=8$; block-saline group, $n=9$; block-morphine group, $n=9$; unblocksaline group, $n=7$; unblock-naloxone group, $n=8$ ).

\section{Behavior}

The mean and SEM levels of freezing to the CS and context are shown in the top and bottom panels, respectively, of Figure 2. Levels of pre-CS freezing in this and remaining experiments were very low $(<10 \%)$, and there were no differences between groups. The left panels show the performances of the control groups infused with saline, morphine, or naloxone before stage II training. These control groups exhibited similar levels of freezing to the CS. The center panels show the performances of the block groups, whereas

CS

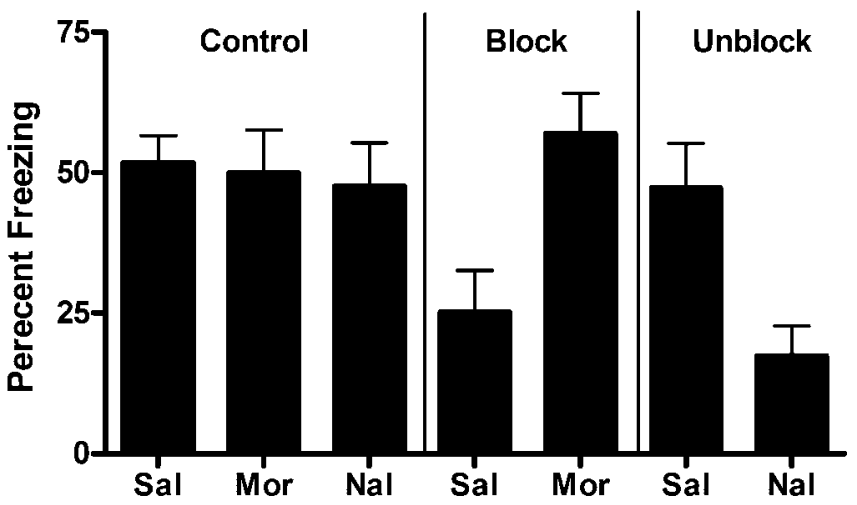

\section{Context}

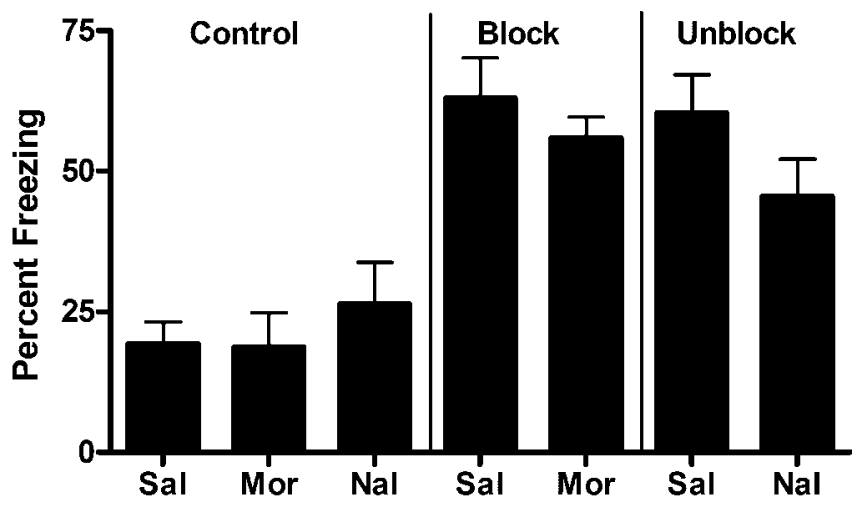

Figure 2. Mean ( \pm SEM) levels of freezing in experiment 1. The behavioral design is shown in Table 1. Top, Freezing to the auditory CS. Bottom, Freezing to the context. There was evidence for blocking of CS fear learning and prevention of blocking by morphine. There was evidence for the unblocking of CS fear and the prevention of unblocking by naloxone. Sal, Saline; Mor morphine; Nal, naloxone. the right panels show those of the unblock groups. There was evidence for blocking because the block-saline groups showed significantly less freezing than the controls $\left(F_{(1,60)}=9.6 ; p<\right.$ 0.05). An infusion of morphine decreased blocking because the block-morphine group showed significantly more freezing than the block-saline group $\left(F_{(1,60)}=10.4 ; p<0.05\right)$. There was evidence for unblocking with the increase in stage II US intensity because the unblock-saline group showed equivalent levels of freezing to the controls $\left(F_{(1,60)}=0.1 ; p>0.05\right)$. Acb infusion of naloxone prevented this unblocking: the unblock-naloxone group showed significantly less freezing than the unblock-saline group $\left(F_{(1,60)}=7.6 ; p<0.05\right)$. No differences in clicker freezing were detected among the control groups $(F<1.0 ; p>0.05)$.

The levels of freezing on the context test suggests that groups receiving stage I training displayed more freezing but that there were no further differences among the groups. The statistical analysis confirmed that the control groups showed significantly less freezing than the groups receiving stage I training $\left(F_{(1,60)}=\right.$ 47.6; $p<0.05)$; however, there were no differences among the control groups nor among the groups receiving stage I training (maximum $\left.F_{(1,60)}=2.7 ; p<0.05\right)$.

Experiment 2: role of Acb opioid receptors in indirect predictive learning

Prediction error can influence associative formation indirectly by determining attention to the CS and hence its subsequent associability with the US (Mackintosh, 1975; Pearce and Hall, 1980). Evidence for such a role in prediction error is that blocking of fear conditioning does not occur after a single compound trial but does occur after two such trials (Mackintosh et al., 1980). According to attentional explanations, blocking does not occur on the first compound trial because the attention allocated to the added CS allows it to associate with the US. However, the small prediction error on that trial causes attention to be withdrawn from the added CS, and hence it fails to associate with the US on the subsequent trial (see also Mackintosh et al., 1977). 
We investigated whether the role for Acb opioid receptors in predictive learning was indirect by infusing an opioid receptor agonist into the Acb on the first, second, or both trials during stage II. The design is shown in Table 1. All groups received stage I training. In stage II, all groups received two CS-shock pairings. Before each stage II trial, groups received an infusion of either morphine or saline. The saline-saline group received an infusion of saline, whereas the morphinemorphine group received an infusion of morphine before both CS-US pairings. The morphine-saline group received an infusion of morphine before trial 1 and an infusion of saline before trial 2. The saline-morphine group received an infusion of saline before trial 1 and an infusion of morphine before trial 2. If infusion of morphine into the Acb removed blocking because it prevented the normal withdrawal of attention from the added CS after the first trial and thus allowed the CS to associate with the US on the subsequent trial, then rats that receive morphine on the first trial and saline on the second trial should fail to exhibit blocking. Furthermore, if the initial trial does cause the withdrawal of attention from the added CS, then rats that receive saline on the first trial and morphine on the second trial should exhibit blocking.

\section{Histology}

Figure 3 shows the location of microinjection tips. One animal was excluded from the experiment because of incorrect cannula placement. Thus, 31 animals were included in the analyses (salinesaline group, $n=8$; morphine-morphine group, $n=8$; saline-morphine group, $n=$ 8 ; morphine-saline group, $n=7$ ).

\section{Behavior}

The mean and SEM levels of freezing on test to the CS (top) and context (bottom) are shown in Figure 4. The morphinemorphine and morphine-saline groups showed significantly more CS freezing than the saline-saline and salinemorphine groups $\left(F_{(1,27)}=12.3 ; p<\right.$ $0.05)$. An infusion of morphine on the first stage II trial was sufficient to prevent blocking: the morphine-saline group did not differ from the morphine-morphine group $\left(F_{(1,27)}<1 ; p>0.05\right)$. An infusion of morphine on the second stage II trial did not prevent blocking because the saline-morphine group did not differ from the saline-saline group $\left(F_{(1,27)}<1\right.$; $p>0.05)$. The bottom panel of Figure 4 shows that these differences in CS freezing were not accompanied by any differences between the levels of context freezing. The statistical analysis confirmed that none of the differences in context freezing were statistically significant $(F<1)$.

These results show that Acb opioid receptors contribute to indirect predictive learning. Rats that received an Acb infu-
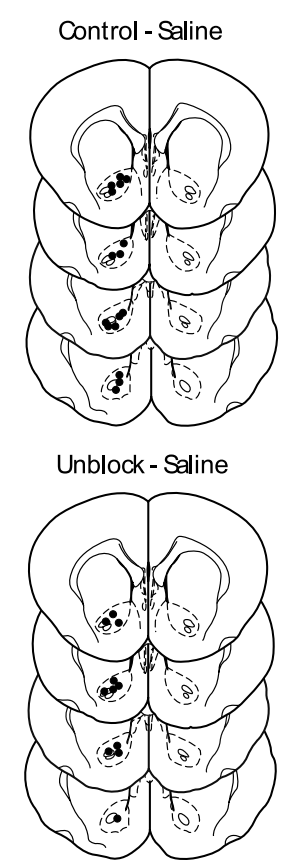
bregma).

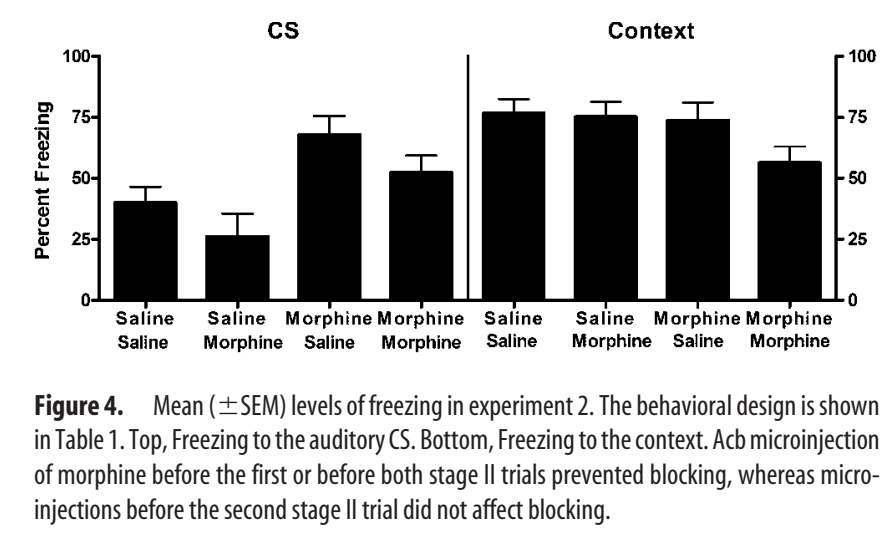

Figure 4. Mean ( \pm SEM) levels of freezing in experiment 2. The behavioral design is shown in Table 1. Top, Freezing to the auditory CS. Bottom, Freezing to the context. Acb microinjection of morphine before the first or before both stage II trials prevented blocking, whereas microinjections before the second stage II trial did not affect blocking.
$+1.0 \mathrm{~mm}$
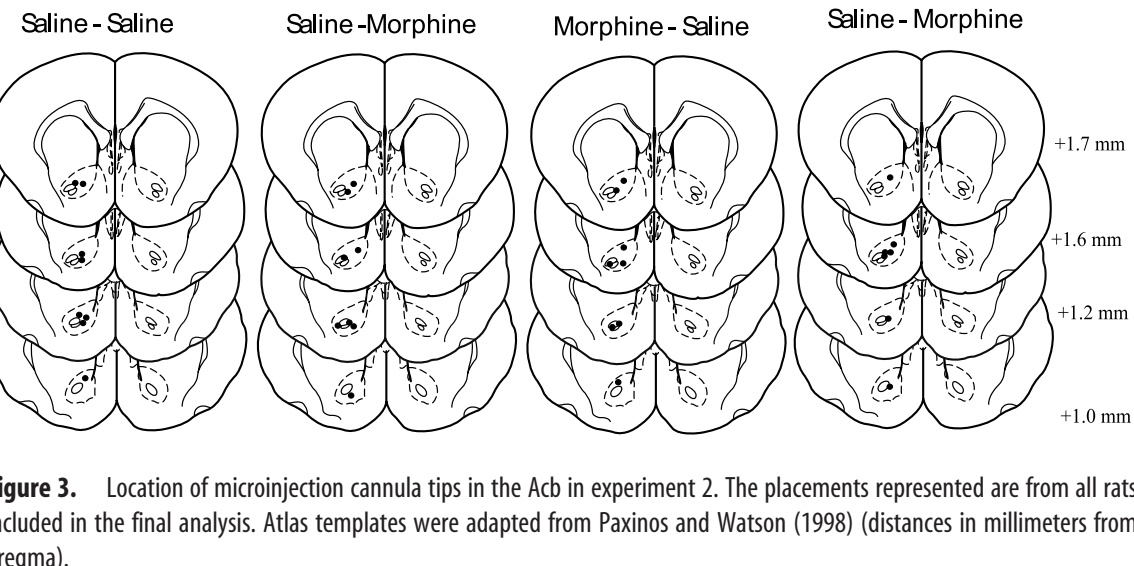

Figure 3. Location of microinjection cannula tips in the Acb in experiment 2. The placements represented are from all rats included in the final analysis. Atlas templates were adapted from Paxinos and Watson (1998) (distances in millimeters from
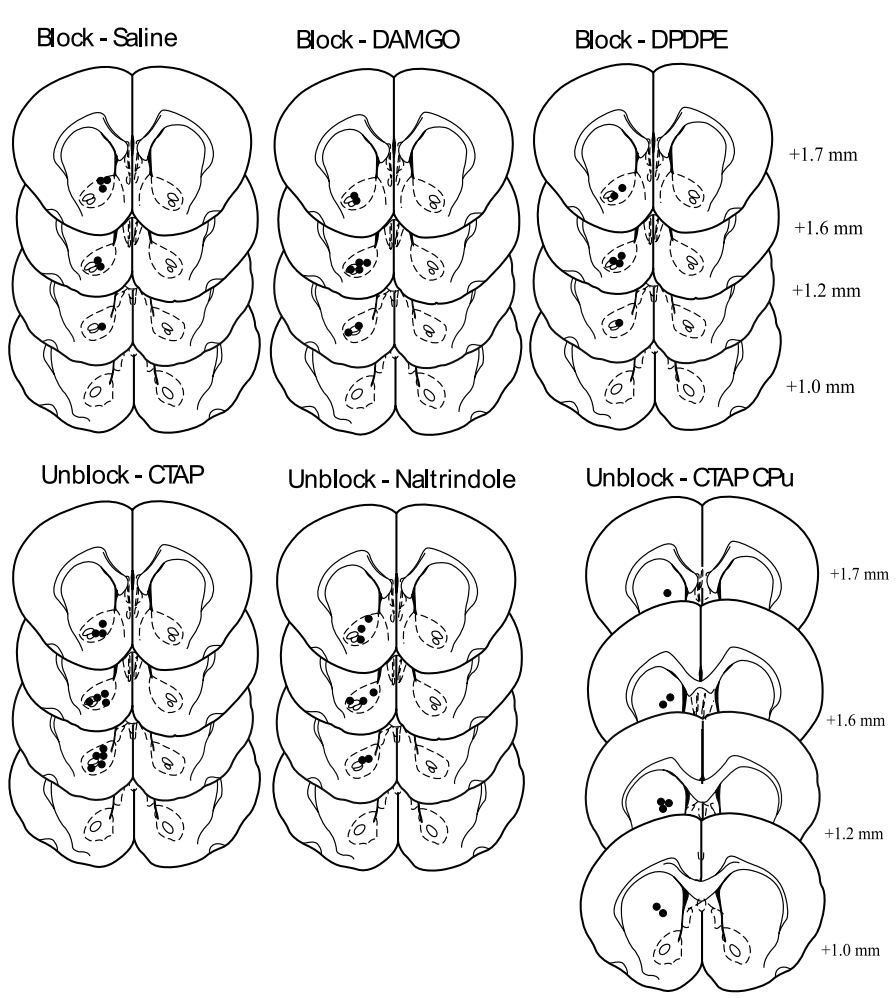

Figure 5. Location of microinjection cannula tips in the Acb in experiment 3a. The placements represented are from all rats included in the final analysis. Atlas templates were adapted from Paxinos and Watson (1998) (distances in millimeters from 
sion of morphine on both the first and the second stage II trials learned more about the added CS than rats infused with saline on these trials. Critically, this attenuation of blocking was attributable to the infusion of morphine on the first but not on the second stage II trial. These results are consistent with attentional explanations that attribute blocking to the role played by prediction error on the first trial in determining attention and hence associative formation on subsequent trials. According to these explanations, blocking occurs on the second trial because the small prediction error on the first trial resulted in a withdrawal of attention from the added CS. Thus, the infusion of morphine on the first trial prevented the loss of attention that underlies the failure of associative formation on the second trial. Additional evidence that morphine acted indirectly on associative formation comes from the failure of morphine to attenuate blocking when administered on the second stage II trial. If morphine had attenuated blocking by acting directly on associative formation, by changing the effectiveness of the US, its administration on the second stage II trial would also have attenuated blocking. However, this did not occur.

Experiments $3 a$ and $3 b$ : role of Acb $\mu$ - and $\delta$-opioid receptors in blocking and unblocking

There are four opioid receptors: $\mu, \delta, \kappa$, and nociceptin (Williams et al., 2001; for review, see McNally and Akil, 2002). Morphine and naloxone are relatively nonselective for these receptor subtypes but show a greater affinity for $\mu$ receptors (Williams et al., 2001). The aims of experiments $3 \mathrm{a}$ and $3 \mathrm{~b}$ were to determine whether the actions of Acb $\mu$ - or $\delta$-opioid receptors were critical for opioid receptor contributions to blocking and unblocking. The design is shown in Table 1 . We used CTAP as a $\mu$-selective antagonist and DAMGO as a $\mu$-selective agonist. We used Naltrindole as a $\delta$-selective antagonist and DPDPE as a $\delta$-selective agonist. Each of these compounds possess excellent selectivity to their respective opioid receptor type (Williams et al., 2001).

\section{Histology}

Figure 5 shows the location of microinjection tips. A total of five animals were excluded from the experiment because of incorrect cannula placement. Thus, 75 animals were included in the analyses (control-saline group, $n=16$; block-saline group, $n=6$; unblock-saline group, $n=11$; block-DAMGO group, $n=8$; block-DPDPE group, $n=6$; unblock-CTAP group, $n=12$; unblock-Naltrindole group, $n=8$; unblock-CTAP CPu group, $n=8)$.

\section{Behavior}

The mean and SEM test levels of freezing to the CS (top) and context (bottom) are shown in Figure 6. There was evidence for blocking of CS fear learning because the block-saline group showed significantly less freezing than the control-saline group $\left(F_{(1,67)}=10.9 ; F_{\mathrm{c}}=p<0.05\right) \cdot \mu$-Opioid but not $\delta$-opioid receptors regulate this blocking because the block-DAMGO group showed significantly more freezing $\left(F_{(1,67)}=8.7 ; p<0.05\right)$ than, whereas the block-DPDPE group did not differ $\left(F_{(1,67)}<1 ; p>\right.$ 0.05 ) from, the block-saline group. The increase in shock intensity from stage I to stage II produced unblocking because the unblock-saline group showed significantly more freezing than the block-saline group $\left(F_{(1,67)}=11.5 ; p<0.05\right) . \mu$-Opioid but not $\delta$-opioid receptors regulate this unblocking. The unblockCTAP group showed significantly less freezing $\left(F_{(1,67)}=26.6 ; p<\right.$ $0.05)$ than, whereas rats in the unblock-Naltrindole group did not differ $\left(F_{(1,67)}<1.0 ; p>0.05\right)$ from, the unblock-saline
CS

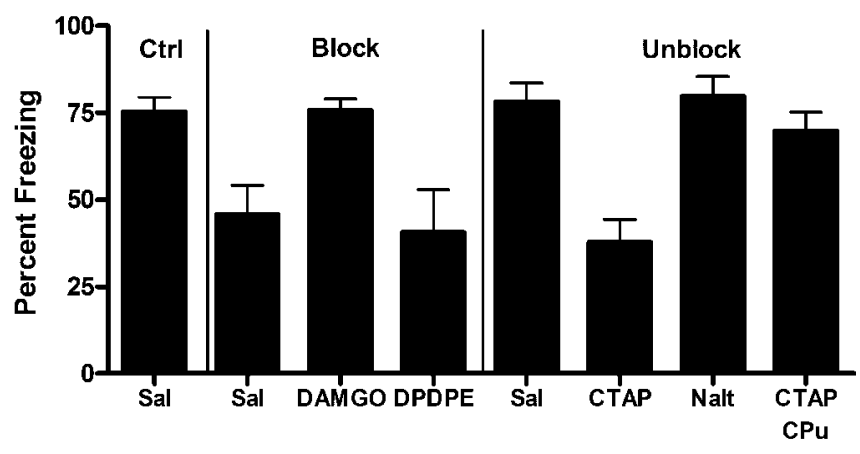

Context

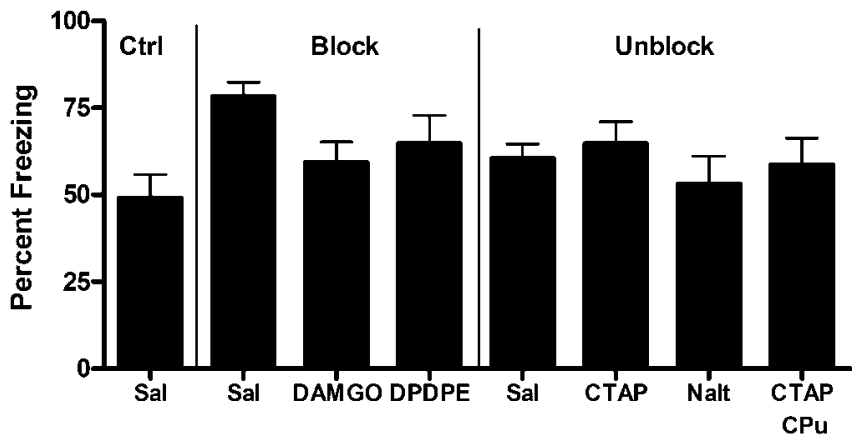

Figure 6. Mean ( \pm SEM) levels of freezing in experiment $3 a$. The behavioral design is shown in Table 1. Top, Freezing to the auditory CS. Bottom, Freezing to the context. There was evidence for blocking of CS fear learning and prevention of blocking by the $\mu$-opioid receptor agonist DAMGO but not the $\delta$ agonist DPDPE. There was evidence for the unblocking of $C S$ fear and the prevention of unblocking by the $\mu$-opioid receptor antagonist CTAP but not the $\delta$ agonist Naltrindole. Ctrl, Control; Sal, saline; Nalt, Naltrindole.

group. Finally, the effect of an infusion of CTAP was specific to its antagonism of $\mu$-opioid receptors in the Acb because infusion into the $\mathrm{CPu}$ failed to affect unblocking: the unblock-CTAP $\mathrm{CPu}$ group did not differ from the unblock-saline group $\left(F_{(1,67)}<1.0\right.$; $p>0.05)$.

The levels of freezing on the context test suggests that groups receiving stage I training displayed more freezing but that there were no further differences among the groups. The statistical analysis confirmed that the control groups showed significantly less freezing than the groups receiving stage I training $\left(F_{(1,67)}=\right.$ 7.5; $p<0.05)$; however, there were no differences among the control groups nor among the groups receiving stage I training (maximum $F=2.8 ; p>0.05$ ).

It is possible that the failure to observe any effect of $\delta$-opioid receptor agonism or antagonism on blocking and unblocking was attributable to the use of a single dose of agonist or antagonist. To assess this possibility, in experiment $3 \mathrm{~b}$ we studied the doseresponse properties of $\delta$-opioid receptor antagonism $(0,2.5,7.5$, and $10 \mu \mathrm{g}$ ) on unblocking. Figure 7 shows the location of microinjection tips for rats in this experiment. There were 36 animals in this experiment (control-saline group, $n=5$; blocksaline group, $n=4$; unblock $-0 \mu$ g group, $n=7$; unblock -2.5 $\mu$ g group, $n=7$; unblock-7.5 $\mu$ g group, $n=7$; unblock-10 $\mu \mathrm{g}$ group, $n=6)$.

The mean and SEM test levels of freezing to the CS (top) and context (bottom) are shown in Figure 8. There was evidence for blocking because the block-saline group showed significantly less fear to the CS than the remaining groups $\left(F_{(1,30)}=4.5 ; p<0.05\right)$. 
There was also evidence for unblocking, because the unblocking groups $(0,2.5,7.5$, and $10 \mu \mathrm{g}$ ) were not significantly different from the control-saline group $\left(F_{(1,30)}<1\right.$; $p>0.05)$. Finally, there was no effect of $\delta$-opioid receptor antagonism on unblocking, because the groups infused with different doses of Naltrindole (unblock$2.5 \mu \mathrm{g}$, unblock-7.5 $\mu \mathrm{g}$, and unblock-10 $\mu \mathrm{g})$ did not differ from the unblock- $0 \mu \mathrm{g}$ group $\left(F_{(1,30)}<1 ; p>0.05\right)$, nor did they differ from each other $\left(F_{(1,30)}<1 ; p>\right.$ $0.05)$. The levels of freezing on the context test suggests that there were no differences between groups. The statistical analysis confirmed that there were no differences between groups in context freezing (largest $\left.F_{(1,30)}=1.8 ; p>0.05\right)$.

This result argues against the possibility that the failure to observe any effect of $\delta$-opioid receptor antagonist on unblocking was attributable to the use of a single dose of antagonist. Together, these results suggest that the role of Acb $\mu$-opioid receptors in predictive fear learning is more important than the role of Acb $\delta$-opioid receptors. However, two caveats bear on interpretation of experiments using $\delta$-opioid receptor agonists and antagonists. First, the effects of $\delta$-opioid receptor manipulations can vary across different assays. For example, peptide versus nonpeptide ligands can have different effects on behavioral measures that have been linked to differences in agonist efficacy (Jutkiewicz et al., 2005). Second, there have been reports of subtypes of $\delta$-opioid receptors (Zaki et al., 1996). For example, the $\delta_{1}$ subtype may display greater affinity for the agonist DPDPE, whereas the $\delta_{2}$ subtype may display greater affinity for the agonist Deltorphin. Additional research is needed to fully examine the role of Acb $\delta$-opioid receptors in predictive fear learning.

\section{Experiment 4: role of Acb $\kappa$-opioid receptors in blocking}

This experiment studied the role of Acb $\kappa$-opioid receptors in modulating blocking of fear learning. $\mu$-Opioid and $\kappa$-opioid receptors have opposing influences on memory, motivation, and pain sensitivity (Spanagel et al., 1990, 1992; Pan et al., 1997; Pan, 1998). The aim of this experiment was to determine whether these opposing influences are also observed in predictive learning. The design is shown in Table 1 . The procedures were identical to those used in experiments 1 and 2, except that the rats received an infusion of a $\kappa$-opioid receptor agonist (U50488H) or antagonist (Nor-BNI) before stage II.

\section{Histology}

Figure 9 shows the location of microinjection tips. Two animals were excluded from the experiment because of incorrect cannula placement. Thus, 44 animals were included in the analyses (control-saline group, $n=8$; control-Nor-BNI group, $n=8$; control-U50488 group, $n=5$; block-saline group, $n=8$; blockNor-BNI group, $n=8$; block-U50488 group, $n=8$ ).

\section{Behavior}

The mean and SEM levels of freezing on test to the CS (top) and context (bottom) are shown in Figure 10. Again, there was evidence for blocking of CS fear because the block-saline group showed significantly less freezing than the control group $\left(F_{(1,38)}=\right.$ $9.5 ; p<0.05)$. Blocking appeared to be prevented by the $\kappa$-opioid receptor antagonist but facilitated by the $\kappa$-opioid receptor agonist. The statistical analysis partly confirmed these observations. The infusions of the $\kappa$-opioid receptor agonist facilitated blocking because the block-U50488 group showed significantly lower levels of freezing than the block-saline group $\left(F_{(1,38)}=4.1 ; p<\right.$ $0.05)$. This shows that effects of $\kappa$-opioid receptor agonists on blocking are the opposite to the effects of $\mu$-opioid receptor agonists: a $\kappa$-agonist facilitates whereas a $\mu$-agonist impairs blocking. However, there was no significant effect of the $\kappa$-opioid receptor antagonist, because the block-Nor-BNI group did not differ significantly from the block-saline group $\left(F_{(1,38)}=3.5 ; p>\right.$ $0.05)$. It is worth noting that the $\kappa$-opioid receptor antagonist Nor-BNI can produce a long-lasting blockade of $\kappa$-opioid receptors. These potential long-lasting effects may have affected our results, but we consider this unlikely because we used control infusions to equate rats on exposures to $\kappa$ agonists and antagonists (see Materials and Methods). There were no statistically significant differences between the levels of freezing among control rats infused with saline, Nor-BNI, or U50488 $(F<1$; $p>0.05)$.

The levels of freezing on the context test suggests that groups receiving stage I training displayed more freezing but that there 


\section{CS}

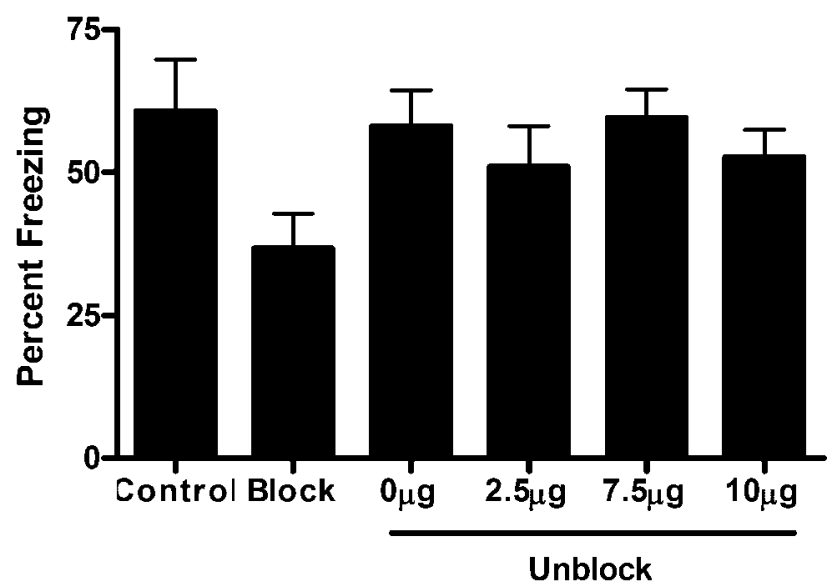

Context

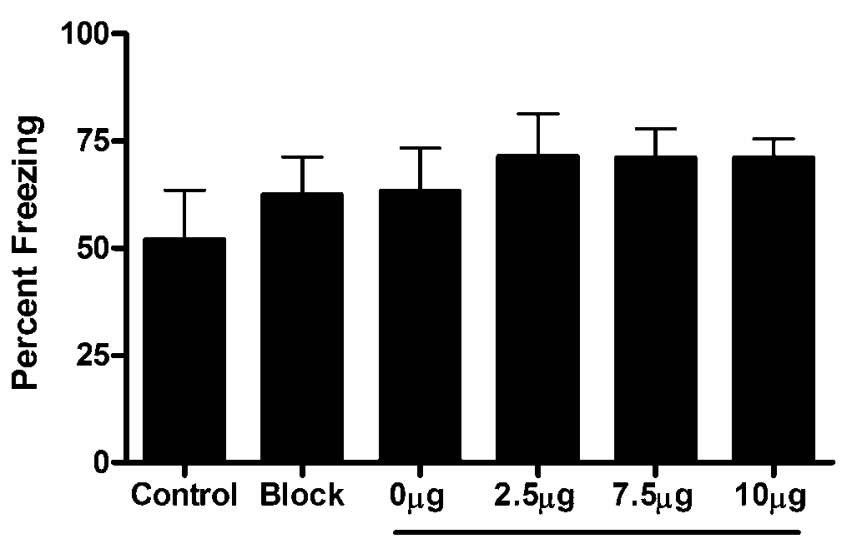

Unblock

Figure 8. Mean ( \pm SEM) levels of freezing in experiment $3 b$. The behavioral design is shown in Table 1. Top, Freezing to the auditory CS. Bottom, Freezing to the context. There was evidence for blocking of CS fear learning and for unblocking. The Acb infusions of the $\delta$ agonist Naltrindole had no effect on unblocking of CS fear conditioning.

were no additional differences among the groups. The statistical analysis confirmed that the control groups showed significantly less freezing than the groups receiving stage I training $(F=19.8$; $p<0.05$ ); however, there were no differences among the control groups nor among the groups receiving stage I training (maximum $F=1.4 ; p>0.05$ ).

\section{Discussion}

Pavlovian fear conditioning is regulated by prediction error: if the error between the actual and predicted US is large, then CS-US associations are formed; if prediction error is small, then the formation of CS-US associations is impaired. We used blocking and unblocking preparations to examine the role of Acb opioid receptors in predictive fear learning. In stage I, rats in the experimental groups received context-shock pairings. In stage II, all rats received CS-shock pairings in that context. Across all of the experiments reported here, previous context conditioning blocked CS fear conditioning (Kamin, 1968). Blocking occurs because the prediction error during stage II is small for the groups receiving stage I training (the context already predicts the US), but this error is large for the control groups. Blocking was prevented (i.e., unblocking occurred) if the intensity of the US was increased from stage I to stage II. Unblocking occurs because the increase in US magnitude increases prediction error during stage II and supports conditioning to the added CS.

Opioid receptors in the Acb play an important role in the blocking and unblocking of fear learning. Blocking of fear learning was prevented by Acb infusions of an opioid receptor agonist (i.e., these infusions permitted normal fear conditioning to the CS in stage II). Conversely, unblocking of fear learning was prevented by Acb infusions of an opioid receptor antagonist (i.e., these infusions prevented fear conditioning to the CS in stage II). These effects of Acb opioid receptor manipulations were specific to regulating learning about the blocked CS because they had no effect on fear learning in the control conditions. Our results also identify the critical opioid receptor subtypes for these Acb contributions to predictive learning. $\mu$-Opioid and $\kappa$-opioid receptors appear especially important for predictive learning. A $\mu$-opioid receptor agonist prevents, whereas a $\kappa$-opioid receptor agonist facilitates, blocking of the added CS by the pretrained context. Conversely, a $\mu$-opioid receptor antagonist prevents unblocking when the introduction of the added CS was accompanied by an increase in the intensity of the shock US from that used to pretrain the context. This opposition between the Acb $\mu$ - and $\kappa$-opioid receptors in predictive learning is consistent with their opposing influences on motivation, memory, and pain sensitivity (Shippenberg and Herz, 1986; Pan et al., 1997; Pan, 1998).

Acb opioid receptors contribute to predictive fear learning by regulating the amount of attention allocated to a CS. Prediction error can have a direct or indirect action on fear conditioning. A direct action occurs because an expected shock in stage II supports less learning than a surprising shock (Rescorla and Wagner, 1972). An indirect action of predictive learning is achieved by selective attention: if prediction error is large, attention to the CS is maintained, and it associates with the US (unblocking); if prediction error is small, attention is initially directed toward the CS but is then withdrawn, and the association is impaired (blocking) (Mackintosh, 1975; Pearce and Hall, 1980). The results of experiment 2 are uniquely consistent with a role for Acb opioids in indirect predictive learning. That experiment demonstrated that infusion of morphine attenuated blocking when administered before the first compound trial but not when administered before the second compound trial. According to attentional models, prediction error acts indirectly on associative formation by determining attention and hence associative formation on subsequent trials. Subjects attend to and learn about the added CS on the initial trial, but then they withdraw attention from that CS because of a small prediction error and thus fail to learn about the CS on subsequent trials. Acb $\mu$-opioid receptor agonists prevent this decline in attention to the CS and allow it to associate with shock on the second trial. Conversely, during unblocking, attention to the CS is upregulated because it is predictive of the increase in reinforcer magnitude. We suggest that Acb $\mu$-opioid receptor antagonists prevent this upregulation of attention and block the CS from associating with shock.

Acb $\mu$-opioid receptors upregulate attention to conditioned stimuli that are predictive of shock, whereas $\kappa$-opioid receptors downregulate attention to conditioned stimuli that are redundant or noninformative predictors of shock. The precise mechanisms through which these learned variations in attention are achieved remain unclear. It is possible that they depend on Acb DA. Acb infusions of the DA agonist D-amphetamine facilitate whereas broad-spectrum DA antagonists or combined infusions of $\mathrm{D}_{1}$ and $\mathrm{D}_{2}$ antagonists prevent blocking (Iordanova et al., 2006). Thus, $\mu$-opioid receptor agonists function like DA recep- 
tor antagonists to prevent blocking. However, this functional similarity contrasts with the effects of Acb $\mu$-opioid receptor activation on extracellular DA levels. Typically, systemic (Di Chiara and Imperato, 1988 ) or Acb infusions of $\mu$-opioid receptor agonists increase extracellular concentrations of DA (Hirose et al., 2005). Nonetheless, according to this line of reasoning, prediction error during fear learning is related to levels of DA in the Acb. High levels of DA are elicited by a fear CS as it comes to predict the US (Young et al., 1993; Guarraci and Kapp, 1999). The high levels of DA provoked by the pretrained CS may cause attention to be allocated to it, and they may concomitantly cause loss of attention to the added, novel CS. During blocking, therefore, Acb infusions of a $\mu$-opioid receptor agonist or of $\mathrm{D}_{1}$ and $\mathrm{D}_{2}$ antagonists mimic a large prediction error and upregulate attention to the added CS, thereby allowing it to associate with the US on subsequent trials. In contrast, infusions of a $\kappa$-opioid receptor agonist or of $\mathrm{D}_{1}$ and $\mathrm{D}_{2}$ agonists mimic a small prediction error and downregulate attention to the added CS, thereby reducing its subsequent associability with the US. Similarly, during unblocking (when the large prediction error maintains attention to the added CS), antagonism of $\mu$-opioid receptors mimics a small prediction error and downregulates attention to the added CS, thereby impairing its subsequent association with the US. These interactions are clearly speculative, and additional research is needed to identify the precise interactions between Acb opioids and DA during indirect predictive fear learning.

The role we have identified for Acb $\mu$-and $\kappa$-opioid receptors in regulating attention to predictors of danger adds to our knowledge of the brain mechanisms for pavlovian fear conditioning. According to current understanding, activation of NMDA receptors in the lateral (LA) and basolateral (BLa) amygdala and recruitment of the signal transduction cascades subsequent to NMDA receptor activation (e.g., $\mathrm{Ca}^{2+}$ and cAMP-dependent signaling) encodes the CS-US relationship during pavlovian fear conditioning. Evidence from single-unit recordings, lesions, and localized pharmacological as well as molecular manipulations support this model of fear learning (Davis, 1992; Fanselow and LeDoux, 1999; Maren, 2001). It suggests that the multimodal CS and US sensory inputs converge on individual amygdala neurons to induce long-term synaptic plasticity and formation of fear memories (Maren and Quirk, 2004). Our data show that the Acb is necessary for fear learning. $\mu$-Opioid and $\kappa$-opioid receptors in the Acb contribute to fear learning by regulating the attention allocated to a CS. These learned variations in attention may be achieved via alterations in the strength of CS inputs to the LA and BLa during fear conditioning, possibly via indirect projections from the Acb to BLa via ventral pallidum and mediodorsal thalamus (Groenewegen et al., 1996). Regardless, these and other recent results (McNally et al., 2004; McNally and Cole, 2006) highlight the need to incorporate mechanisms for predictive learning into contemporary models of the neural mechanisms of pavlovian fear conditioning.

The Acb comprises distinct subterritories, including the shell,
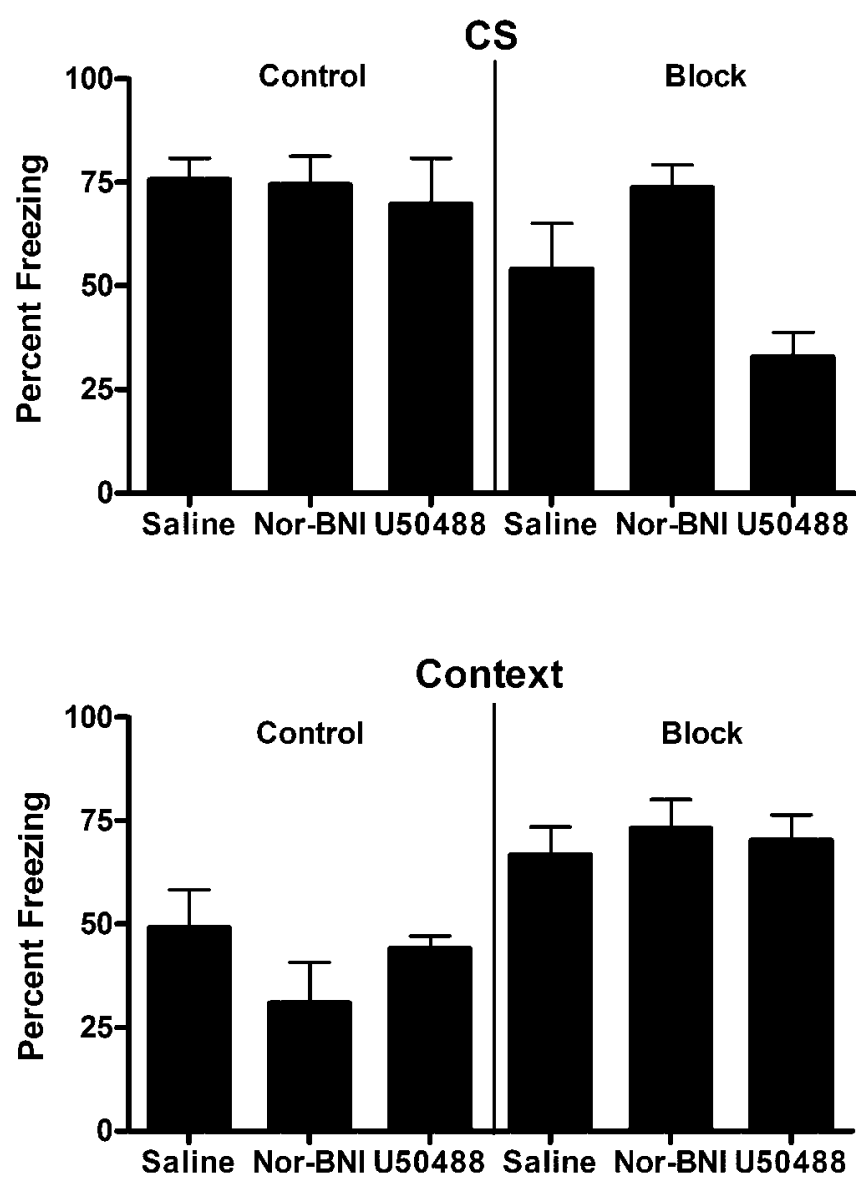

Figure 10. Mean ( \pm SEM) levels of freezing in experiment 4. The behavioral design is shown in Table 1. Top, Freezing to the auditory CS. Bottom, Freezing to the context. There was evidence for blocking of $\mathrm{CS}$ fear learning and the facilitation of blocking by the $\kappa$-agonist U50488. 
core, and rostral pole (Zahm and Brog, 1992). These have distinct anatomical and functional properties. It was not possible to differentiate between these different territories in these experiments. The cannula placements showed a distribution across both the core and shell. The Acb shell region has been implicated previously in learned variations in attention (Weiner, 1990). Additional research is needed to identify the potential different contributions of the Acb core and shell to predictive fear learning.

The ability to detect and learn about predictive relationships between events allows us to use the past to predict the future and to adjust our behavior accordingly. Learning about predictive relationships depends on what we already know about the events in the relationship: if an outcome is unexpected, we learn to attend to cues that predict its occurrence; if the outcome is already expected, information provided by other cues about its occurrence is redundant, and we learn to ignore them. These experiments show for the first time that $\mu$ - and $\kappa$-opioid receptors in the Acb regulate such attentional learning during pavlovian fear conditioning.

\section{References}

Blanchard RJ, Blanchard DC (1969) Crouching as an index of fear. J Comp Phys Psychol 67:370-375.

Davis M (1992) The role of the amygdala in fear and anxiety. Annu Rev Neurosci 15:353-375.

Di Chiara G, Imperato A (1988) Drugs abused by humans preferentially increase synaptic dopamine concentrations in the mesolimbic system of freely moving rats. Proc Natl Acad Sci USA 85:5274-5278.

Dickinson A (1980) Contemporary animal learning theory. Cambridge, UK: Cambridge UP.

Fanselow MS, LeDoux JE (1999) Why we think plasticity underlying Pavlovian fear conditioning occurs in the basolateral amygdala. Neuron 23:229-232.

Groenewegen HJ, Wright CI, Beijer AVJ (1996) The nucleus accumbens: gateway for limbic structures to reach the motor system. Prog Brain Res 107:485-511.

Guarraci FA, Kapp BS (1999) An electrophysiological characterization of ventral tegmental area dopaminergic neurons during differential Pavlovian fear conditioning in the awake rabbit. Behav Brain Res 99:169-179.

Hirose N, Murakawa K, Takada K, Oi Y, Suzuki T, Nagase H, Cools AR, Koshikawa N (2005) Interactions among mu- and delta-opioid receptors, especially putative delta(1)- and delta(2)-opioid receptors, promote dopamine release in the nucleus accumbens. Neuroscience 135:213-225.

Iordanova MD, Westbrook RF, Killcross S (2006) Dopamine in the nucleus accumbens regulates error-correction in associative learning. Eur J Neurosci, in press.

Jutkiewicz EM, Walker NP, Folk JE, Rice KC, Portoghese PS, Woods JH, Traynor JR (2005) Comparison of peptidic and nonpeptidic \{delta\}opioid agonists on $\left[{ }^{35} \mathrm{~S}\right] \mathrm{GTP} \gamma \mathrm{S}$ binding in brain slices from SpragueDawley rats. J Pharmacol Exp Ther 312:1314-1320.

Kamin LJ (1968) “Attention-like" processes in classical conditioning. In: Miami symposium on the prediction of behavior: aversive stimulation (Jones MR, ed), pp 9-33. Miami: University of Miami.

Mackintosh NJ (1975) A theory of attention: variations in the associability of stimulus with reinforcement. Psychol Rev 82:276-298.

Mackintosh NJ, Bygrave DJ, Picton BMB (1977) Locus of the effects of a surprising reinforcer in the attenuation of blocking. Q J Exp Psychol 29:327-336

Mackintosh NJ, Dickinson A, Cotton MM (1980) Surprise and blocking: effects of the number of compound trials. Anim Learn Behav 8:387-399.
Maren S (2001) Neurobiology of Pavlovian fear conditioning. Annu Rev Neurosci 24:897-931.

Maren S, Quirk GJ (2004) Neuronal signalling of fear memory. Nat Rev Neurosci 5:844-852.

McNally GP, Akil H (2002) Opioid peptides and their receptors: overview and function in pain modulation. In: Neuropsychopharmacology: a fifth generation of progress (Davis K, Charney D, Coyle JT, Nemeroff C, eds), pp 35-46. New York: Lippincott Williams and Wilkins.

McNally GP, Cole S (2006) Opioid receptors in the midbrain periaqueductal gray regulate prediction errors during Pavlovian fear conditioning. Behav Neurosci, in press.

McNally GP, Pigg M, Weidemann G (2004) Blocking, unblocking and overexpectation of fear: opioid receptors regulate Pavlovian association formation. Behav Neurosci 118:111-120.

O’Doherty JP, Dayan P, Friston K, Critchley H, Dolan RJ (2003) Temporal difference models and reward-related learning in the human brain. Neuron 38:329-337.

Pagnoni G, Zink CF, Montague PR, Berns GS (2002) Activity in human ventral striatum locked to errors of reward prediction. Nat Neurosci 5:97-98.

Pan ZZ (1998) $\mu$-Opposing actions of the $\kappa$-opioid receptor. Trends Pharmacol Sci 19:94-98.

Pan ZZ, Tershner SA, Fields HL (1997) Cellular mechanism for antianalgesic action of agonists of the kappa-opioid receptor. Nature 389:382-385

Paxinos G, Watson C (1998) The rat brain in stereotaxic coordinates, Ed 4. Sydney: Academic.

Pearce JM, Hall G (1980) A model for Pavlovian learning: variations in the effectiveness of conditioned but not of unconditioned stimuli. Psychol Rev 87:532-552.

Rescorla RA (1988) Behavioral studies of Pavlovian conditioning. Annu Rev Neurosci 11:329-352.

Rescorla RA, Wagner AR (1972) A theory of Pavlovian conditioning: variations in the effectiveness of reinforcement and nonreinforcement. In: Classical conditioning II: current research and theory (Black AH, Prokasy WF, eds), pp 64-99. New York: Appleton Century Crofts.

Shippenberg TS, Herz A (1986) Differential effects of mu and kappa opioid systems on motivational processes. NIDA Res Monogr 75:563-566.

Spanagel R, Herz A, Shippenberg TS (1990) The effects of opioid peptides on dopamine release in the nucleus accumbens: an in vivo microdialysis study. J Neurochem 55:1734-1740.

Spanagel R, Herz A, Shippenberg TS (1992) Opposing tonically active endogenous opioid systems modulate the mesolimbic dopaminergic pathway. Proc Natl Acad Sci USA 89:2046-2050.

Stevens J (1986) Applied multivariate statistics for the social sciences. Hillsdale, NJ: Erlbaum.

Tobler PN, O’Doherty JP, Dolan RJ, Schultz W (2006) Human neural learning depends on reward prediction errors in the blocking paradigm. J Neurophysiol 95:301-310.

Waelti P, Dickinson A, Schultz W (2001) Dopamine responses comply with basic assumptions of formal learning theory. Nature 412:43-48.

Weiner I (1990) Neural substrates of latent inhibition: the switching model. Psychol Bull 108:442-461.

Williams JT, Christie MJ, Manzoni O (2001) Cellular and synaptic adaptations mediating opioid dependence. Physiol Rev 81:299-343.

Young AM, Joseph MH, Gray JA (1993) Latent inhibition of conditioned dopamine release in rat nucleus accumbens. Neuroscience 54:5-9.

Zahm DS, Brog JS (1992) On the significance of subterritories in the "accumbens" part of the rat ventral striatum. Neuroscience 50:751-767.

Zaki PA, Bilsky EJ, Vanderah TW, Lai J, Evans CJ, Porreca F (1996) Opioid receptor types and subtypes: the delta receptor as a model. Annu Rev Pharmacol Toxicol 36:379-401. 